\title{
LATE ABSTRACTS
}

P.30.01.1

Poster Session: 30 August, Board: 191

Acta Cryst. (2005). A61, C496

Surface: A Micro Instrument for in situ XRD-XRF and Optical Measurements

Paolo Plescia ${ }^{1}$, Gabriel M. Ingo ${ }^{1}$, Andrea Bianco $^{2}$, Alessandro Biasini ${ }^{2},{ }^{1} I S M N-C N R$, National Research Council of Italy Institute for the Study of Nanostructured Materials, Rome Italy. ${ }^{2}$ Assing Research Center, Rome Italy. E-mail: paolo.plescia@ismn.cnr.it

The "SURFACE MONITOR" instrument is an innovative and integrated portable XRD-XRF apparatus combined with a reflectance spectro-photometrical system. The instrument was designed by ISMNCNR and Assing in the frawork of an European project (EUREKAEurocare) "Surface Monitor", aimed to develop a portable system of multispectral analysis for the not destructive and not invasive characterisation of archaeological artefacts. Concerning the XRD analysis, the innovative design of the SURFACE MONITOR equipments allows to carry out the characterisation by using a ThetaTheta configuration from -10 to $140^{\circ} 2 \Theta$. XRD analysis can be also carried out in angular scan and in energy scan modality. The data collected by the detector are elaborated in an innovative 3D mode, indeed, for each step, the XRF spectrum is first stored and then all the fluorescence spectra are represented in a three-dimensional mode, by plotting the energy on the abscissas, the scan angle on ordinates in a horizontal plane and the measured intensity in the vertical plane ( $\mathrm{Z}$ coordinates). By plotting the results in this mode, the user can friendly decide "to cut" the XRD spectrum to the wavelength of more interest, within the used energetic range in the experiment and to filter the scattering that reduces the signal-to-noise ratio. According to this new approach, the XRD spectrum is obtained not to as a single window of energy, but using all the available energies and therefore it turns out extremely more resolved, also using lowest powers. In order to validate this new instrument a large scale characterisation of metal archaeological artefacts has been carried out also for gaining deep insight into the micro-chemical structure of the stratified corrosion layers and of the bulk metallurgical features. This innovative apparatus and approach has evidenced that SURFACE MONITOR with its optical, XRD and XRD facilities have significant potential in studies of the corrosion products of archaeological silver and copper objects for their stabilisation and conservation.

\section{P.30.01.2 Poster Session: 27 August, Board: 208}

Acta Cryst. (2005). A61, C496

Crystal Structures of Uricase Complexed with its Real Substrate and Product

Akio Takénaka ${ }^{\mathrm{a}}, \mathrm{M}$. Tofazzal Hossain ${ }^{\mathrm{a}, \mathrm{d}}$, Ella Czarina Magat Juan ${ }^{\mathrm{a}}$, Kaoru Suzuki $^{\mathrm{b}}$, Tamotsu Yamamoto ${ }^{\mathrm{c}}$, Shigeyuki Imamura ${ }^{\mathrm{c}}$, Takeshi Sekiguchi ${ }^{\mathrm{b}},{ }^{\mathrm{a}}$ GraduateSchool of Bioscience and Biotechnology, Tokyo Institute of Technology. ${ }^{\mathrm{b}}$ College of Science and Engineering, Iwaki Meisei University. ${ }^{\mathrm{c}}$ Asahi Kasei Corporation, Japan. ${ }^{\mathrm{d}}$ Department of Biochemistry and Molecular Biology, Rajshahi University, Bangladesh.E-mail: atakenak@bio.titech.ac.jp

Uricase is a copper-containing enzyme that catalyzes the conversion of uric acid to allantoin during the breakdown of purines in some mammalian species, as well as in amphibians and most fishes. Uricase from small organisms, however, does not require any metal ion or cofactor for its catalytic activity. Since humans do not produce uricase, this enzyme may be useful as a drug to prevent uric acid accumulation.

To clarify the reaction mechanism, three X-ray structures of uricase from a prokaryote Arthrobacter globiformis, and of complexes with its substrate uric acid and with a product allantoin have been solved at 2.0, 1.9 and $1.9 \AA$ resolutions, respectively. In every structure, the two subunits are associated to form a ring-shaped dimer, and the two dimers are stacked on each other to complete a cylinderlike tetramer with a long tunnel at the center. The site of uric acid and allantoin binding to the protein are the same, located at interface between two subunits of the ring.

Keywords: X-ray structure, uricase, Arthobacter globiformis

\section{P.30.01.3 \\ Poster Session: 27 August, Board: 209}

Acta Cryst. (2005). A61, C496

Antimony Oxides: the Pyrochlore-type Structure Revisited

Maria-Ondina Figueiredo, Crystallography and Mineralogy Centre, IICT, \& CENIMAT, New Univ. Lisbon, 2829-516 Caparica, Portugal. E-mail: crysmin@clix.pt

Antimony oxides display a variety of structural arrangements with different stoichiometries resulting from two stable speciations for $\mathrm{Sb}$ ions. They commonly occur as minerals with well known crystal structure, but there are still questions regarding stibiconite - a very rare yellow mineral with pyrochlore-type structure and approximate formula $\mathrm{Sb}_{3} \mathrm{O}_{6}(\mathrm{OH})$ [1]. Great interest has been focused on synthetics because of antimony speciation in relation to color and crystal structure [2], and important ion exchange properties of Sb-pyrochlores were recently pointed out [3].

When studying yellow glazes from majolica-type tiles using X-ray absorption spectroscopy at the Sb K-edge [4], the possibility of an Sbpyrochlore being the final responsible for the actual coloring was advanced, despite antimony being added during the manufacture process as bindheimite, $\mathrm{Sb}_{2} \mathrm{~Pb}_{2} \mathrm{O}_{7}$ (giallo di Napoli).

An analysis is presented on the two possible crystallographic descriptions for a pyrochlore-type array under the usual cubic space group that could account for an anomalous intensification of 111 reflection for Sb-pyrochlore within the glaze and simulataneously correlate with XANES data.

[1] Vitaliano C.J., Mason B., Amer. Min., 1952, 37, 982. [2] Stewart D.J., Knop O., Ayasse C., Woodhams F.W.D., Canad. J. Chem., 1972, 50, 690. [3] Luca V., Griffith C.S., Blackford M.G., Hanna J.V., J. Mat. Chem., 2005, 15, 564. [4] Figueiredo M.O., Veiga J.P., Silva T.P., Mirao J.P., Pascarelli S., SRMS-4, August 23-28, 2004, Grenoble/France, poster.

\section{P.30.01.4 Poster Session: 30 August, Board: 192}

Acta Cryst. (2005). A61, C496

Enzyme Ribonucleotide Reductase. The Paradigm of Enzyme Inhibition by Furanone Derivatives

Nuno M. F.S.A. Cerqueira, Pedro A. Fernandes, Maria João Ramos, REQUIMTE, Faculdade de Ciências do Porto, Universidade do Porto, Rua Campo Alegre, 687, 4169-007 Porto, Portugal. E-mail: NScerqueira@hotmail.com

Ribonucleotide Reductase (RNR) is the enzyme responsible for the physiological reduction of all four ribonucleotides to 2'deoxyribonucleotides. The activity of this enzyme is therefore essential for the stability and survival of the cell, since it is directly involved in DNA synthesis and repair. This key role makes it an attractive target for anti-tumor, anti-viral and anti-bacterial therapies, having been largely studied for the past few years[1-4]. Several 2'substituted-2'-deoxyribonucleotides are potent inactivators of the enzyme ribonucleotide reductase (RNR), that destroy the essential tyrosil radical located in subunit R2 or/and add covalently to subunit $\mathrm{R} 1$. In the absence of reductors the inactivation of the former is related with the alquilation of a furanone derivative that is detected in solution by UV spectroscopy. The furanone is a degradation product of a keto-deoxyribonucleotide that is an intermediate of the inhibitory mechanism of a wide group of 2'-substituted inhibitors. Interestingly the same keto-deoxyribonucleotide is also a proposed intermediate of the natural substrate during the reduction mechanism but, by some reason it does not dissociates from the active site and does not inactivate the enzyme [5]. This study was dedicated to this paradigm and allowed to evaluate the interaction between the enzyme and this keto-deoxyribonucleotide. A model containing a complete R1 subunit was used to model the desire minimums and to deal with such a big system a QM/MM method was employed. The results allowed to conclude that the release of the keto-deoxyribonucleotide is dependent on the charged/neutral nature of the atoms/group that is/are attached to carbon C-2' of the deoxyribonucleotide and their tendency to dissociate through solution.

[1] Fernandes P.A., Eriksson L.A., Ramos M.J., Theor.Chem. Acc., 2002, 108, 352. [2] Cerqueira N.M.F.S.A., Fernandes P., Ramos M.J., Eriksson L., Journal of Molecular Structure: Theochem, 2004, 709, 53-65. [3] Cerqueira 


\section{LATE ABSTRACTS}

N.M.F.S.A., Fernandes P., Ramos M.J., Eriksson L., Journal of Computational Chemistry, 2004, 16, 2031-2037. [4] Cerqueira N.M.F.S.A., Fernandes P., Ramos M.J., Eriksson L., Journal of Biophysical Journal, submitted. [5] Cerqueira N.M.F.S.A., Pereira S., Fernandes P., Ramos M.J., Accounts for Medicinal Chemistry, accepted.

Keywords: Ribonucleotide reductase, furanone derivatives, model

\section{P.30.01.5 Poster Session: 25 August, Board: 227}

Acta Cryst. (2005). A61, C497

Structure and Properties of Aminoacid Adducts with 3d Metals Leonore Wiehl ${ }^{\mathrm{a}^{*}}$, Jürgen Schreuer ${ }^{\mathrm{a}}$, Eiken Haussühl ${ }^{\mathrm{a}}$, Katarina Removic-Langer ${ }^{\mathrm{b}}$, ' Institut für Mineralogie / Kristallographie. ${ }^{\mathrm{b}}$ Physikalisches Institut, Universität Frankfurt am Main, Germany. Email: L.wiehl@kristall.uni-frankfurt.de

Compounds with low-dimensional magnetic interactions can be designed by combining spin bearing metals with organic molecules. The metal ions are connected e.g. to amino groups or carboxylate groups of the organic ligand and two different metal ions may be bridged via the organic molecule, thus allowing for an electron transfer between the metals. Depending on size and geometry of the organic molecules and the amount of metal salt, many different arrangements are realized, e.g. dimers, trimers, chains [1] or even 2dimensional sheets [2]. The different metal-metal distances and the chemical surroundings characterize the type and strength of magnetic interaction.

In adducts with betaine the carboxylate group can bridge two different metal ions. With aminoacids like histidine or glycine, the nitrogen atoms of the amino groups present additional bridging options.

Crystals of betaine and aminoacid adducts with $\mathrm{MeX}_{2}(\mathrm{Me}=\mathrm{Cu}$, $\mathrm{Mn} ; \mathrm{X}=\mathrm{Cl}, \mathrm{Br}$ ) were grown from aqueous solution. The crystal structures will be presented together with magnetic susceptibilities, showing low-dimensional interactions and/or antiferromagnetic ordering at low temperature.

[1] Schreuer J., Haussühl S., Z. Krist., 1993, 205, 313. [2] Lu J.Y., Lawandy M.A., Li J., Inorg. Chem., 1999, 38, 2695.

Keywords: structure determination, betaine, magnetic ordering

\section{P.30.01.6 Poster Session: 26 August, Board: 201}

Acta Cryst. (2005). A61, C497

Structure Discovery Using an Integrated Microfluidic Crystallization System

Andy May, Shelley Godley, Kathy Yokobata, Kyle Self, Kevin Farrell, Paul Wyatt, Fluidigm Corporation, 7100 Shoreline Court, South San Francisco, CA 94080.

Use of the three-dimensional structures of biological macromolecules is now a key component of many research programs. Identifying conditions for the growth of diffraction quality crystals of target proteins remains one of the main bottlenecks in structure determination. The TOPAZ ${ }^{\mathrm{TM}}$ system provides a rapid and efficient path to structure through the use of integrated fluidic circuits (IFCs), which enable the routine setup of sub-nanoliter crystallization experiments. IFCs are miniaturized fluidic devices that control the precise metering of fluid through the use of integrated valves controlling the flow between interconnected channels and chambers. Crystallization in TOPAZ IFCs is effected through microfluidic freeinterface diffusion ( $\mu$ FID). $\mu$ FID provides a complementary approach to crystallization by traditional methods, such as vapor diffusion.

Data will be presented describing evaluation studies carried out at academic and pharmaceutical customer sites. These studies include comparisons of screening experiments carried out using the TOPAZ system and vapor diffusion on a variety of samples. Results from screening experiments demonstrate the highly reproducible reagent distribution and crystallization behavior within experiments conducted using TOPAZ IFCs. Paths for successful translation of sub-nanoliter crystallization hits to larger-scale diffraction-quality crystals will also be discussed, including examples from experiments carried out at Fluidigm and independently at customer sites.

The presentation will also discuss ongoing product development at Fluidigm, highlighting paths for future additions and improvements to the TOPAZ system.

P.30.01.7 Poster Session: 29 August, Board: 223

Acta Cryst. (2005). A61, C497

EM and X-ray Studies of HupR, A Response Regulator from the NtrC Family

Karen Davies, Louise Johnson, Catherine Vénien-Bryan, Lab of Molecular Biophysics, Department of Biochemistry, University of Oxford, Oxford, UK. E-mail:karen@biop.ox.ac.uk

HupR, a member of the NtrC response regulator family, enhances transcription of a membrane-bound hydrogenase in response to environmental change. It is a $53 \mathrm{kDa}$ protein composed of 3 domains: An N-terminal receiver domain, a central putative AAA + ATPase domain, and C-terminal DNA binding domain. Regulation of transcription occurs via a two-component signalling pathway resulting in the phosphorylation of the receiver domain. In most $\mathrm{NtrC}$-like proteins, phosphorylation causes the oligomerisation of the central domain, which activates ATP hydrolysis and promotes interaction with the $\sigma^{54}$ RNA polymerase (RNAP). Transcription is initiated using the energy released from ATP hydrolysis.

HupR is an unusual member of the NtrC family, as phosphorylation inhibits HupR-dependent transcription. We have calculated a low-resolution structure of the full-length protein using electron crystallography. This model shows HupR crystallised as a dimer. The volume is half that expected suggesting only part of the protein was imaged. We believe this part is the central domain. In addition, 3D crystals of the receiver domain $\pm \mathrm{BeF}_{3}^{-}$have been obtained. Preliminary results show the domain has the classic receiver fold with an extended $\alpha 5$. The protein forms a weak dimer which is strengthened by $\mathrm{BeF}_{3}{ }^{-}$. The dimer interface involves $\beta 5 \& \alpha 5$.

Keywords: electron crystallography, response regulators, NtrC

\section{P.30.01.8 Poster Session: 26 August, Board: 202}

Acta Cryst. (2005). A61, C497

Crystal and Molecular Structure of 2, 5 - bis(butoxy) 1,4-bis (biphength ethynyl) benzene and 2, 5-bis (Octyloxy) 1, 4-bis (biphenyl ethynyl) benzene S. A. Chawdhury ${ }^{1}$, Paul R . Raithby ${ }^{2}$, Muhammad Younus ${ }^{3},{ }^{1}$ Sylhet International University, Sylhet, Bangladesh. ${ }^{2}$ University of Bath, $U$. $K .{ }^{3}$ Shahjalal University of Science and Technology, Sylhet, Bangladesh.

Conjugated organic polymers are semiconductors which are used in wide range of devices such as light emitting diodes and photocells. Conjugated organic polymers have two major emissive states singlets and triplets Radiative emission from triplet series is spin forbidden, so that only emission from the singlet state occurs. Recently the synthesis and investigation of spectrospic properties have been undertaken in Department of Chemistry, Shahjalal University of Science and Technology, Sylhet, Bangladesh and Department of Chemistry, University of Bath, U. K. The monomeric precursors have been structurally characterized by the single crystal X-ray crystallography. X-ray analysis of the two monomers (a) 2,5 (butoxy) 1,4 - bis(biphenylethynyl)benzene, $\mathrm{C}_{42} \mathrm{H}_{36} \mathrm{O}_{2}$ (b) $2,5-$ bis(octyloxy) 1,4 - bis(biphenylethynyl) benzene, $\mathrm{C}_{50} \mathrm{H}_{34} \mathrm{O}_{2}$ have been carried out to find the linear arrangements of the monomeric units in the polymers derived from them.

Crystal data of the compound (a) $\mathrm{C}_{42} \mathrm{H}_{36} \mathrm{O}_{2}$, Triclinic, P1 with a $=9.2290(3) \mathrm{A}^{0}, \mathrm{~b}=9.5120(4) \mathrm{A}^{0}, \mathrm{C}=19.2850(7) \mathrm{A}^{0} \alpha=99.206(2)$ ${ }^{0} . \beta=100.980(2)^{0} \quad \gamma=105.393(2)^{0}, \quad Z=2, \quad \rho_{0}=1.222 \mathrm{Mg} / \mathrm{m}^{3}$, absorption coefficient $0.923 \mathrm{~m} \mathrm{~m}^{-1}, \mathrm{~F}(000) 612$, crystal size $0.50 \mathrm{x}$ $040 \times 0.10 \mathrm{~mm}^{3}$, teta range for data collection 2.98 to 27.60 ; final $\mathrm{R}=$ 0.0609 for 7130 independent reflections (b) $\mathrm{C}_{50} \mathrm{H}_{36} \mathrm{O}_{2}$ is controsymmetric, monoclinic $\mathrm{P} 2_{1} / \mathrm{C}$ with $\mathrm{a}=16.8910(8) \mathrm{A}^{0}, \mathrm{~b},=$ 5.4580 (3) $\mathrm{A}^{0}, \quad \mathrm{C}=22.6030(13) \mathrm{A}^{0}, \beta=106.490,\left(2^{0}\right), \quad \mathrm{Z}=2$, $\rho=1.142 \mathrm{Mg} / \mathrm{m}^{3}$, absorption coefficient $0.667 \mathrm{~nm}^{-1}, \mathrm{~F}(000)=740$, crystal size $0.45 \times 0.15 \times 0.03 \mathrm{~mm}$, teta range for data collection 3.71 to 24.44 degrees. Final $\mathrm{R}$ indices 0.0577 for 3252 independent reflections.

Both structures were solved by direct methods and refined by full matrix least squares methods.

Keywords: X-ray, crystal structure, semiconductors 